\title{
Target audience of the popular science information in media: peculiarities and classification
}

\author{
K. R. Bilohrats \\ Lviv Polytechnic National University, Lviv, Ukraine \\ Corresponding author. E-mail: khrystyna.r.bilohrats@lpnu.ua \\ Paper received 11.02.19; Accepted for publication 17.02.19.
}

\begin{abstract}
https://doi.org/10.31174/SEND-HS2019-192VII32-15
\end{abstract}
Abstract. The classification of groups of creators and recipients of popular science information is considered. In article described the features of the target audience of information consumers. Mass media channels, which disseminate information about scientific achievements, are described. Suggested the classification of consumers of popular science information.

Keywords: popularization of science, science information, mass media channels, classification of target audience.

Popularization of science can influence on people of different social groups and on their decisions. Dissemination of interesting and readable, existing or newly created materials about the scientific achievements can form desire of young recipients to engage in scientific researches in various fields in their future life. For an adult audience it is an opportunity to get information that can help in some way to solve everyday issues, to expand own horizons and gain knowledge that can be useful in their work or life.

The peculiarities of the target audience and the popularization of science have been researched by numerous Ukrainian scientists, including N. Bogomolova, S. Girik, V. Zdorovega, N. Zelinska, A. Boyko, O. Konovets, D. Filonenko and others. A. Koloyev also was writing about typological features and types of popular science periodicals in his article [7]. N. Diveyeva in her thesis investigated the popularization of science as a form of communication under the conditions of new information technologies and the market relations [3]. Scientific and popular sites in the system of mass media, their typological and profile peculiarities were described by E. Makarova in her dissertation work [8].

N. Zelinska has written in her work, that for a long time it has been considered that science is developing only when scientists publish fundamental works, solid monographic researches, however, modern practice demonstrates a decisive turn to a «small form», which in a certain sense has significant advantages over the «big form» - efficiency, rather economical expenses and democracy [6].

Actively developing direction of professional publications of scientific periodicals, many scientists abroad are trying to promote their own researches not only among their colleagues, but among a wide audience as well, trying to convey the importance and peculiarity of their own scientific achievements.

The Academic Explanatory Dictionary of the Ukrainian language provides the following definitions of the term «popularization»: - submission of something in a clear, accessible form; - distribution of achievements of national and world culture among people, - promotion of knowledge etc., popularizing of smth. [10, p. 239.].

In the DSTU standards in the section on the types of periodic and continuing publications there are such definitions: «Popular science magazine is a magazine that contains publications on the bases of science, as well as achievements in the field of science, technology, culture, art and practical activities, presented in a readable for non-professional-readers form» [4, p. 19 - 20]. Immediately after that, the definition of a popular magazine has been given: «This is a magazine that contains educational publications on various issues of culture, art, sports, life, and other areas of knowledge of social and practical activities for satisfying the interests of the non-professional readers» $[4$, p. 20$]$.

In the state standard almost the same definition of the terms «popular science» and «popular magazines» is given, however, we consider that popular magazines can not only be such that promote information and have an educational value, because the popularity is determined by the requirements of recipients and the number of editions.

The spread of popular science information S. Girik considers being a real weapon against propaganda of pseudoscientific and antiscientific concepts, and various falsifications [2]. It's difficult not to disagree with such a statement, however, it's worth remembering that only respected scientists should refute the publications, which contain anti-scientific facts, because such scientists can write clearly and in a popular way about complicated scientific facts, and they can explain easily and availably them to journalists, who will work with specific scientific issues, as recipients, having received information, can not always objectively evaluate it and understand how truthful it is.

$\mathrm{N}$. Bogomolova suggests that the audience is being formed by separate people belonging to different social groups; therefore the researcher points out on the following features of Mass Media audience:

- huge, massive;

- spontaneous, unorganized;

- unstable;

- anonymous for the communicator;

- is divided at the time of perception of the message to many small groups;

- without clear boundaries, but with a certain rhythm [1, p. 134].

We can add to the statement that affiliation with certain social groups does not guarantee absolute coincidence in interests and preferences, therefore even within a certain group people may belong to smaller groups. We agree that the audience of recipients is large and massive, thus it can be divided into separate groups while perceiving the information. However, in our opinion, if the specific features of the target audience, to which the communicant 
refers in his message, have been defined clearly, it is possible to determine its boundaries, which not for long, but, nevertheless, will remain clear.

In the joint work of V. Rizun, A. Boyko, O. Konovets, N. Zelinska and B. Potyatynyk - the manual «Scientific communication in Mass Media: a workshop» - the problems of scientific communication are being described [9]. It is written there that complex topics can be of public interest only if the journalist knows how to submit and to evaluate the scientific information [9]. This means that journalists should understand the methods and scientific research data, skillfully transforming scholar message so that it would be clear and interesting for the audience for which this message has been prepared.

The authors of the «Scientific communication in Mass Media» divide scientific journalism into three types:

1. specialized scientific publications, issued by scholars for scientists and intended for a highly specialized circle of readers;

2. the work of scientific journalists and special correspondents, whose reports are published on the pages of publications devoted to researches, in special scientific programs;

3. the work of correspondents who do not specialize in scientific issues - they may be employees of the news department, politicians or environmentalists, who sometimes cover scientific topics [9].

$\mathrm{V}$. Zdorovega noted that the audience needs fresh and extraordinary information, which is described easily and wittily. Readers of the newspaper or the magazine can be attracted by harmonious and interesting design, layout, color, unexpectedness, and titles with intrigue or wit, thoughtful headings, unobtrusive style and the selectivity of words [5]. These factors in the complex cause the audience's interest. Specific means of interest are based on the peculiarities of the diverse interests of the reader or audience. Gender, age, social status, regional factor, education, level of intellectual development, hobbies should be taken into account. If we talk about universal ways of attracting attention in journalism, then on their basis - the novelty of the fact and the novelty of the idea or, what usually happens, their special combination. They interact in different ways, depending on the type of media, the type of publication, the kind of television broadcast. This is a very wide range of journalistic information - from the presentation of the only news, and broad flows of facts to analytical headings, special programs on television and radio, analytical publications [5].

D. Filonenko claims that today the segment of popular science publications can not be considered as being in high demand by the audience. Serious science, unlike pseudoscientific, sensational materials, does not provoke the interest of numerous readers. To his mind, such phenomenon takes place due to some unpreparedness of the audience to accept objective, empirically proven information [11]. We consider that the problem is not only that recipients are not interested in «high» science, but that in Ukraine scientists are not got used to promote their own researches among the large audiences, and disseminate information only among their colleagues. There are also problems related to the reluctance of journalists/owners/managers of periodicals and channels to disseminate scientific information that they find not sensa- tional. As we know, the audience will be interested in the facts offered by mass media, but if the editorial policy of the media does not include the dissemination and promotion of scientific information, then the potential target audience will not learn about new information that relates to scientific researches. D. Filonenko points out that, due to the almost total absence of competition between scientific publications, a full-scale study of the audience has not been conducted yet, and this leads to the irrational distribution of materials in editions [11].

In the process of observing of all the scientific-popular information in Ukraine, we can make conclusions about modern channels of dissemination of such information. We offer the following classification of information dissemination:

- periodicals (magazines «Kunst», «Worldview», «Country of Knowledge», «Experiment», «Psychologies», etc.);

- radio:

$\circ$ broadcasting («This man was Albert Einstein», «ABC», etc.).

O information in the news blocks of radio channels;

- television:

○ sitcoms («Myth busters», « Mind Games» and others);

$\circ$ information in the news blocks of TV channels;

- Internet:

○ sites («My science», «Scientific room», «Ukrainian Scientific Club» and others);

o sections on the sites (for example, the section «Science» on the site «BBC Ukraine»);

○ social pages (for example, «I love science», «Science»);

o collections of movies in the archives of websites.

As we can see, Internet has the greatest potential for distributing popular science information in a variety of ways; probably these opportunities will be replenished with new means.

Without the thorough analysis of the target audience the work of the editorial department may not be effective enough. We offer to classify the audience of popular science information in the media according to the certain characteristics: age, personal interests and professional needs. Of course, such a division may very nominal.

Characteristics by age for:

- children,

- teenagers,

- adults.

Children are interested in everything around them, and of course, the information they receive depends on their environment. Adults influence on what the children are watching and reading, therefore, such an age group can be called dependent on the elderly audience.

Teenagers may be interested in information that will help to design certain scientific devices, make unforgettable experiments.

Adult audience is the most diverse, because people can be interested in useful tips that will make their everyday work easier, and in information that can help in professional life, or increase their own knowledge.

\section{By personal interest:}

- random recipients, 
- recipients, who are interested in specific information for a certain period of time,

- amateurs/connoisseurs.

Random recipients of information encounter it without seeking, but can continue to read or watch what they are interested in. Of course, they may eventually move to another group.

Recipients, who are searching for certain information, are constantly looking for everything related to an issue they are interested in. Having found the required information, they can shift to another group of personal interests.

Amateurs or connoisseurs of popular science publications/broadcasts may be subscribers or regular viewers.

\section{For professional needs:}

- students,

- specialists of the professions adjacent, or related to the information,

- experts,

- scientists.

Students are looking for the available materials to help them in studying.

Specialists of the adjacent professions seek popular scientific information for professional interests, and ex- perts search for the information how the sphere in which they work, is being popularized.

Scientists likely will not seek popular science materials for professional interest, but they can do so to know how to popularize their achievements and how other scholars do it.

The popularization of science in Ukraine is not so active as it is abroad, but science-pop programs are being shown on television, are being broadcast on the radio, sites and pages in social networks are being created in Internet, periodicals, that may be of interest to those who seek information, and for those who would see it accidentally, are being issued.

Almost always recipients use scientific-popular information as a mean of self-education, to a lesser extent - to find out how popular science achievements are being promoted. In order to promote the science in Ukraine, it's necessary for scientists to be interested in disseminating their achievements among the public, and for journalists to provide truthful information, because if they use wrong facts or manipulate them, the trust of the audience will be lost.

\section{REFERENCES}

1. Bogomolova N. N. Social psychology of mass communication: Handbook for the Higher school students / N. N. Bogomolova - M.: Aspect Press, 2008. - P. 191.

2. Girik S. Science-pop as a weapon against pseudoscience // Historical truth / S. Girik. - [Electronic resource]. - Access mode:

http://www.istpravda.com.ua/columns/2012/05/3/83395/ (Date of the application 07.11.2018)

3. Diveeva Natalya Valeryevna. Popularization of science as a kind of mass communications in the conditions of new information technologies and market relations: author's abstract. ...of the candidate of philological sciences: 10.01.10 / Diveeva Natalya Valeryevna; [Voronezh State University].Voronezh, 2015- P. 18.

4. DSTU 3017: 2015 Edition. The main types. Terms and Definitions [Text]. - Replacement DSTU 3017-95; valid from 07/01/2012. - Kyiv: State Enterprise «UkrNDNTS», 2016 IV, P. 38.

5. Zdorovega $\mathrm{V}$. Theory and methodology of journalistic creativity: Handbook / V. Zdorovega. - Lviv: PAIS, 2000. - P. 180.

6. Zelinska N. Scientific publishing in Ukraine: history and current state: Handbook for the Higher schools students / N. Zelinska - Lviv: Svit, 2002. - P. 268.

7. Koloyev A.S. Scientific-educational publications as a typological niche [Electronic resource] / A. S. Koloyev. - Access mode: http://mediascope.ru/node/1089.

8. Makarova E. E. Science-popular sites in the media system: typological and profile features: author's abstract. Dissertation on getting the $\mathrm{PhD}$ [Electronic resource] / E. E. Makarova. Access mode: http://mediascope.ru/taxonomy/term/396.

9. Scientific communication in mass media: workshop / layout: A.A. Boyko, N.V. Zelinska, O. F. Konovets. - Lviv: Ukrainian Academy of Printing, 2009. - P. 124.

10. Dictionary of the Ukrainian language: in 11 volumes.Volume 7, 1976. - P. 239.

11. Filonenko D. Scientific-popular periodicals of Ukraine: problems of audience formation / D. Filonenko // Works of the research institute of preschool studies. - 2013. - Issue 3. P.403-413. 